\title{
DAS RUAS ÀS REDES: ANÁLISE SOBRE O LAB.RIO DA PREFEITURA DA CIDADE DO RIO DE JANEIRO ${ }^{1}$
}

\author{
João Catraio Aguiar ${ }^{2}$
}

\begin{abstract}
Resumo
O objetivo deste artigo é analisar o programa Laboratório de Participação (Lab.Rio), política pública desenvolvida pela Prefeitura da Cidade do Rio de Janeiro. Como hipótese, acredita-se que tal projeto surgiu devido às tendências recentes em políticas públicas (policy), em comunicação, e na política como um todo (politics). Tais tendências serão analisadas de forma a montar o cenário que antecede e promove/incentiva o surgimento do Lab.Rio. $\mathrm{O}$ método utilizado para analisar essa política pública foi o da análise histórica e conjuntural, trabalhando com a história recente, mas também usando estudos e teorias que analisem as tendências mencionadas. A construção do artigo foi do mais geral, das mudanças mais genéricas, em direção da mudança específica, que foi a criação da política pública "Lab.Rio". A principal conclusão é que a Prefeitura da Cidade do Rio de Janeiro (PCRJ) envereda agora no governo eletrônico (E-Gov), com inovações importantes tendo em vista o cenário contemporâneo.

Palavras-chave: Políticas Públicas; Governo Eletrônico; Participação Social; Comunicação Política; Lab.Rio.
\end{abstract}

\begin{abstract}
The aim of this article is to analyze the program "Laboratório de Participação", public policy developed by the Municipality of the City of Rio de Janeiro. As hypothesis, it is believed that this project has appeared due to the recent tendencies in policy, in communication, and in politics. These tendencies will be analyzed in order to recreate the scenario that precedes the creation and foster the appearance of the Lab.Rio. The method used to investigate this public policy was the conjuncture and historical analysis that precedes it, working with the recent history, but also using studies and theories that analyze at least one of the mentioned tendencies. The construction of this article has been from the most general, of general changes, towards the specific change, which was the creation of the public policy "Lab.Rio". The main conclusion is that the Municipality of the City of Rio de Janeiro (PCRJ) is embarking now in the electronic government (E-Gov), with important innovations having in mind the contemporary scenario.
\end{abstract}

Keywords: Public Policy; Social Movements; Political Communication; Electronic Government; Ágora Rio.

\section{Resumen}

El objetivo en este artículo es analizar el "Laboratório de Participação" (Lab.Rio), política desarrollada desde el Ayuntamiento de la Ciudad de Rio de Janeiro. Como hipótesis, se cree que el proyecto se he presentado debido a las tendencias recientes en políticas de gobierno (policy), en comunicación, y en la política (politics). Serán analizadas las dichas tendencias a fin de que sea construido el escenario que antecede e incentiva la aparición del Lab.Rio. El procedimiento utilizado para analizar esta política fue el análisis histórico y coyuntural, trabajando con la historia reciente, pero también utilizando estudios y teorías que analicen las tendencias. La construcción del artículo fue del más general, de los cambios más genéricos, en dirección de lo cambio específico, que fue la creación de la política "Lab.Rio". La principal conclusión es que el Ayuntamiento de la Ciudad de

\footnotetext{
${ }^{1}$ DOI deste artigo: 10.5380/recp.v6i2.39744.

2 Doutorando em Ciência Política pelo Instituto de Estudos Sociais e Políticos da Universidade do Estado do Rio de Janeiro. Cursa Especialização em Políticas Públicas e Gestão Governamental na Escola de Governo da Universidade Cândido Mendes. Mestre em Relações Internacionais pela Universidade do Estado do Rio de Janeiro. Bacharel e Licenciado em Ciências Sociais pela Universidade Federal do Rio de Janeiro. Foi professor de Sociologia no Colégio Pedro II e de Relações Internacionais na Universidade Católica de Petrópolis.
} 
Rio de Janeiro (PCRJ) embarcase ahora en el gobierno electrónico (E-Gov), con importantes innovaciones teniendo en mente el escenario contemporáneo.

Palabras-clave: Politicas Publicas; Gobierno Electrónico; Participación Societal; Comunicación Politica; Lab.Rio.

\section{INTRODUÇÃO}

O presente trabalho visa analisar a política pública de participação instituída recentemente pela Prefeitura da Cidade do Rio de Janeiro (PCRJ), cujo nome é "Laboratório de Participação"; doravante, Lab.Rio ${ }^{3}$. Para entender esta iniciativa é preciso pensar tendências políticas e culturais atuais, assim como os meios tradicionais de se estimular a participação. Inicialmente, o projeto “Ágora Rio” surgiu, e, em seguida é criado o Lab.Rio; que congrega o primeiro e outras quatro ações, chamadas de "experimentos". Pretende-se mostrar a importância do contexto no surgimento e na fixação da política pública. Pode-se inferir que há uma inovação, o que não dá o direito de afirmar categoricamente que a PCRJ manterá o perfil pró-governo eletrônico, ou se esse perfil será alterado caso uma mudança política ocorra na cidade. Todavia, o estudo verifica-se como útil a todos que acompanham debates acadêmicos e políticos sobre a democracia e as formas de participação social.

No processo decisório em geral se divide em atores oficiais e não oficiais, em que os primeiros são principalmente os 3 poderes, dentro deles, comitês, agências, burocracias; na democracia representativa liberal, assim, a participação da sociedade civil é mediada pelo voto e por mecanismos institucionais, logo, indireta (BIRKLAND, 2011). Sobre o ciclo das políticas públicas, também há oportunidade de participação não só na definição de qual a agenda a se tratar politicamente, via voto; como também através de avaliação sobre as políticas implementadas. A Accountability envolve eleições e a participação na representação, em sua vertente vertical; na sua vertente horizontal envolve agências estatais, que regulam ações (O’DONNELL, 1988). O "Data.Rio", o portal de dados abertos da PCRJ, faz accountability horizontal; enquanto o "Rio sempre presente", que tem um modelo híbrido de marketing público com ouvidoria, faz accountability vertical em momento não-eleitoral.

A ênfase da PCRJ em meios virtuais, que estão ligados às possibilidades da Era da Informação, fez com que as informações da temporada cultural "Rio 450" e dos megaeventos

\footnotetext{
3 A política pública vocacionada para a participação do Lab.Rio aparece como um dos 10 links em destaque visual, no sitio prefeitura.rio, junto com: Carioca Digital; Portal da Prefeitura; 1746; Cidade Olímpica; Centro de Operações do Rio; data.rio; meudominio.rio; Rio 450 Anos; Rio Sempre Presente. Há ainda outros 14 links sem ser em destaque, entre eles Conselho da Cidade e Procon Carioca, que tem algum grau de participação social. Isto marca a importância que a PCRJ dá a estas ações municipais. A formatação da página referida está circunscrita ao período de final de 2014 até novembro de 2015, quando a revisão deste artigo foi finalizada.
} 

Janeiro.

de 2016 "Jogos Olímpicos e Paralímpicos de Verão" tivessem sítios na internet. A união entre accountability vertical com participação e uso do governo eletrônico esteve presente ainda em 2014, antes do Lab.Rio, com o aplicativo "Rio+", que transformava ideias em 12 projetos a serem levados adiante pelo município. Existem formas de accountability conduzidas mais pela sociedade, e outras mais pelas instituições políticas; e traduz-se ela como transparência, prestação de contas, e muitas outras formas.

Nas sociedades atuais há ajustes mútuos entre atores na formulação; e assim meios, objetivos, e a forma como o processo de ação pública se dá fica em função da articulação entre agentes (MASSARDIER, 2003). Portanto, até em países com modelo representativo clássico há a pressão por democratização, que foi lida em diversos momentos como uma proposta de democracia direta, meio de deter autoritarismos, possíveis na representação. Partindo dessa perspectiva entende-se as ações políticas descentralizadas, de autogoverno, de decisão plural e de democracia direta como bases para a eficiência política e para seu caráter democrático (PATEMAN, 1992). A deliberação teve predominância de uma visão com muita ênfase na decisão, e na contemporaneidade teorias têm enfatizado a importância do espaço público, da participação, da argumentação, e das concepções de justiça (AVRITZER, 2000).

Com o tempo, acadêmicos pensam em formas híbridas, com elementos representativos e elementos participativos, que unem elementos de administração centralizada com cooperação, colaboração e deliberação; representadas no conceito de "governança" (FUNG, 2006). Variados desenhos institucionais surgem, delegando autoridade e responsabilidade deliberativa ao povo; e essa deliberação empoderada pode ser: inserida na organização política ou autônoma, pode ser recorrente ou um evento único, pode ser diretamente implementado ou ser submetido à aprovação (GASTIL; JOHNSON, 2015). Nova participação é viabilizada com novas formas de se organização político-sociais; diferente dos movimentos que vigiam até meados do século passado. Os ciclos de movimentos sociais são muitas vezes pontuados por grandes momentos em que eles se reorganizam ou repensam-se.

No Brasil dos anos 1970 e 1980 os temas da redemocratização e acesso aos serviços públicos são os mais fortes; na segunda metade dos 1980 movimentos se institucionalizam; nos 1990, os mais fortes são os rurais; na década de 2000, ascendem os movimentos de anti e alterglobalização (GOHN, 2011). Recentemente, ascendem movimentos ligados à 
identidade e à afirmação de determinados direitos não tão garantidos e/ou ausentes de parcela da população. Destacam-se também Anonymous, Black Blocks, Movimento Passe Livre, entre outros; que são fenômenos que maturaram nos anos 2000. A ausência de transições políticas, a péssima condição social, etc., impeliram a mudanças na "Primavera Árabe”, em 2011, mas, a tecnologia só alterou como as ações foram conduzidas, e não a razão por trás das ações (MCKEEVER; RAPPORT, 2013: 121-134).

Vale lembrar que a internet começou a se popularizar nos anos 1990, e ao longo da década de 2000 que as mídias digitais sociais e alguns aplicativos específicos começaram a ser populares. Ainda assim, a televisão predomina (98,5\% dos domicílios em 2011) mais que os computadores pessoais (45\% dos domicílios em 2010), que junto com lan-houses, celulares (principalmente através de 3Gs em smartphones) foram principais fontes de acesso à internet no país; gerando consequências nas eleições brasileiras de 2010 e nos protestos de 2013, em que o ativismo aumentou enormemente (MIZUKAMI; REIA; VARON, 2014: 23-46; 60-75, passim). Mudam as tecnologias, transformam-se os movimentos.

\section{DAS RUAS...: POLÍTICAS PÚBLICAS VOLTADAS PARA A PARTICIPAÇÃO E OS MOVIMENTOS}

Se desde 1971 há o Fórum Econômico Mundial, desde 2001 há o Fórum Social Mundial, que promoveu grandes debates de anti e alterglobalização. Se nos anos 1980 a redemocratização era importante, as Diretas Já (1983-1984) eram sinal disso. Nos anos 1990, os movimentos sociais conjunturais, de ideologia e ligados a um problema social se unem nas passeatas do "Fora Collor". Movimento parecido ocorrerá nas mobilizações contra privatizações dos anos 1990 e contra os aumentos de passagens dos transportes públicos, nas Jornadas de Junho de 2013. Todavia, no caso brasileiro, uma cultura política tendente à personalização impeliu à concentração das mídias; fazendo com que muitas vezes as pessoas somente reforçassem suas posições políticas, mais que fizessem esforços para revisarem, quando necessário, suas posições políticas (CERVI, 2013: 11-30).

Nesse contexto, um dos maiores desafios brasileiros é tornar a política pública uma instituição, desvinculando a mesma de determinada figura política que, a partir da ação governamental "pessoalizada", capitaliza votos e prestígio. Alguns passos foram dados em diferentes regiões do país. Na cidade do Rio de Janeiro, desde os anos 1930 existiram associações de bairro, desde os anos 1950 florescem as associações de moradores de localidades de baixa renda, como a Comissão de Moradores das favelas Pavão-Pavãozinho e 

Janeiro.

Cantagalo. Lideranças começam a surgir das associações existentes, tal como Jó Rezende nos anos 1980, que veio a ser candidato a vice-prefeito junto da candidatura à prefeito de Roberto Saturnino Braga, que estava na carreira política desde 1962.

A gestão carioca de Saturnino Braga (1986-1988) teve como uma das prioridades a descentralização administrativa com participação popular, consubstanciada nos Conselhos Governo-Comunidade, para fiscalizar e eleger prioridades da prefeitura, reunindo representantes de associações de bairro, de moradores, etc. (BRAGA; BRAGA, 2015). Estrangulado o governo pela ruptura do prefeito com o partido que pertencia quando eleito, por ausência de maioria na Câmara de Vereadores, pelas chuvas de 1988, pela hiperinflação, e pelo veto federal ao rolamento da dívida do município, o governo municipal se dissolve e com ele as experiências participativas. Há ainda casos no interior do Estado do Rio de Janeiro e em no sertão nordestino, em outro momento, após a Constituição Federal de Outubro de 1988 ser promulgada. A experiência não ficou restrita à gestão municipal inicialmente Partido Democrático Trabalhista (PDT), depois ocupada pelo Partido Socialista Brasileiro (PSB).

No interior do Estado mencionado, as Leis Orgânicas de alguns municípios sublinharam a importância da participação, e isso foi traduzido em gestões com partidos diversos. No caso de Pargo, surgiu o Conselho Municipal de Associação de Moradores, que discutiu temas diversos como orçamento, transportes, etc.; no caso de Sereno, surgem Conselhos Municipais para lidar com temas específicos, como Mulher, Criança e Adolescente, Saúde; em ambos os municípios, as experiências participativas se iniciam nos anos 1990, e estiveram presentes movimentos sociais e a ação de Igrejas, em especial Católica e Batista (BEZERRA, 2012). Coalizões lideradas pelo Partido dos Trabalhadores (PT), de 1993 a 1999, em Porto Alegre, desenvolveram experiências participativas também.

Um exemplo é o projeto Cidade Constituinte, similar aos Conselhos Municipais já abordados. Nesse caso tendo por objetivo discutir o planejamento urbano e orientar o Plano Diretor de Desenvolvimento Urbano e Ambiental na cidade. O Orçamento Participativo (OP), também desenvolvido em Porto Alegre, na gestão Olívio Dutra (PT), entre 1989 e $1992^{4}$, foi muito estudado pelo mundo. Consiste em uma assembleia deliberativa de atividade recorrente, que funciona com plenárias de prestação de contas, apresentação e formulação

\footnotetext{
${ }^{4}$ E seria seguida nas gestões subsequentes do PT que vão até 2002: Tarso Genro (1993-1996, 2001-2002); Raul Pont (1997-2000); João Verle (2002-2004). Mesmo com a reversão da hegemonia política, com a ascensão do Partido Popular Socialista, com José Fogaça (2005-2008), depois PMDB (2009-2010); e em seguida com o PDT e José Fortunati (2010-), mantém-se como política de Estado o Orçamento Participativo.
} 
de propostas, definição de prioridades, etc.; os maiores participantes são os moradores da cidade interessados em melhorias a serem conduzidas pelo poder público. Em 2000, por volta de 100 experiências de OP existiam no Brasil, principalmente situadas nas regiões Sul e Sudeste; e em 2007 surge a Rede Brasileira de Orçamento Participativo, para disseminar a boa prática de gestão local urbana. Há ainda outras dimensões nacionais.

As Conferências Nacionais que se debruçam sobre políticas públicas variadas existem desde o Estado Novo brasileiro, desde 1941, porém, elas têm sido mais abrangentes, inclusivas e participativas desde 2003, tendo impacto sobre a produção legislativa (POGREBINSCHI; SANTOS, 2011). Recentemente a presidência do Brasil, liderada por Dilma Rousseff (PT) trabalhou para efetivar a Política Nacional de Participação Social, ampliar o número de usuários da Internet e reduzir a exclusão digital, instituiu o Marco Civil da Internet (SUPPO, 2015). Deliberative Pooling; de James Fishkin; Listening to the City, de Nova Iorque; o policiamento comunitário de Chicago: são exemplos de governança alternativa que empodera os cidadãos (FUNG, 2006).

Em geral, as políticas participativas estiveram associadas com gestões municipais de partidos considerados de esquerda e/ou de centro-esquerda. Os casos de coalizões seguem essa mesma lógica à esquerda, sendo, muitas vezes, composições de partidos de tendências diversas, porém afastados do ideário da direita. O Lab.Rio surge com uma coalizão liderada pelo Partido do Movimento Democrático Brasileiro, e com a presença dos partidos citados anteriormente, durante o segundo mandato municipal de Eduardo Paes (2013-2016).

\section{3. ... ÀS REDES: TENDÊNCIAS RECENTES EM POLÍTICA E CULTURA}

A análise de conjuntura, tal como feita por Betinho, enfocando acontecimentos, atores, relações de forças, estruturas, leva em consideração dimensões internas e externas das unidades políticas (SOUZA, 2009). Nesse sentido, pretende-se, aqui, fazer não só a análise do que existiu previamente na Cidade do Rio de Janeiro, internamente, e no Brasil, ao qual pertence a unidade política carioca, como também analisar tendências globais que incidem sobre o caso que será analisado. No mundo de hoje, das empresas transnacionais e dos regionalismos, o território acaba por ceder lugar a solidariedades das redes de relações, mais ancoradas em identidade e etnia do que em soberania e instituições; mecanismos políticos multilaterais e Estados passam a não ter meios de lidar com determinados problemas/conflitos, e, além disso, de não ser mais os únicos espaços onde se governa (BADIE, 1995). De acordo com Pierre Lévy (1999), novas mídias fazem surgir uma nova 
cultura, a cibercultura, que propiciou a ascensão da democracia eletrônica, com mais participação, mais desconcentração e deslocalização. $O$ mesmo autor enfatiza as possibilidades sócio-políticas em torno da inteligência coletiva, que é a rede colaborativa de saberes e saber-fazer que se desenvolve no ciberespaço.

Essas relações, todavia, ocorrem em sociedades cada vez mais marcadas pelo consumo; e a obtenção de mercadorias eletrônicas faz parte disso. A sociedade de consumo e a cultura de consumo têm diferentes indícios: individualismo; consumo de/para massas; valorização da liberdade/escolha individual; comoditização da realidade; alta descartabilidade de mercadorias; etc. (BARBOSA, 2008). Inaugurada essa nova sociabilidade capitalista, a cidadania seria aumentada conforme as pessoas consigam mais acesso aos produtos (GARCÍA CANCLINI, 2006), evitando privação relativa, por exemplo. Assim, consumidores e cidadãos seriam categorias interligadas.

Como pensar hoje essa "triangulação" entre mídias, política e consumo? Isso pode ser respondido através da convergência midiática: relação cada vez mais estreita entre jornalismo, rádio, televisão e demais mídias com o espaço cibernético, a internet. A convergência de mídias surge quando ascende uma cultura participativa, envolvendo diversos suportes midiáticos (são exemplos smartphones e televisão digital); ampliando interação entre consumidores e produtores de mídia, muitos se tornando transceptores, isto é, receptores e emissores ao mesmo tempo (JENKINS, 2008). Assim, surge a mídia disseminável, que impele a novos meios de circulação da informação, tanto "de cima para baixo" quanto "de baixo para cima", ampliando a participação, principalmente através do fenômeno da "viralização" de determinados conteúdos (FORD; GREEN; JENKINS, 2013).

Além da "convergência", da mídia mais facilmente disseminável, surge também uma série de mudanças na internet, chamada de "Web 2.0", tal como Tim O’Reilly a batizou, que envolve o uso disseminado de redes sociais, de aplicativos livres e abertos, blogs, canais de compartilhamento de arquivos, etc. Ela surgiu conforme a internet virou plataforma midiática ${ }^{5}$, afetando a Economia Política da Comunicação, impelindo conglomerados midiáticos a repensar seus métodos de lidar com audiências (CABRAL, 2011). As tecnologias mais recentes - principalmente ligadas à informática e à internet - redefinem relações sociais,

\footnotetext{
${ }^{5}$ Algumas empresas têm tentado adequar-se à convergência e à interatividade, próprias das transformações citadas neste texto, um exemplo é a British Broadcasting Company, que fez reformas em 2001 e 2006, e refez seus projetos para nova forma de relação com o público (BENNETT; MEDRADO; STRANGE, 2012).
} 
conforme redes se estabelecem, dando maior importância para conhecimento e comunicação, fazendo surgir a sociedade informacional (CASTELLS, 2002).

O "ator em rede" poderia ter uma feição mais à maneira política, como os Estados no multilateralismo; poderia ter feição mais ao lucro, como as empresas transnacionais, e poderia ter uma feição mais comunitária; de qualquer forma, as redes singram do público ao privado e vice-versa (COLONOMOS, 2004). Seja pela institucionalização, seja pela disseminação não-institucionalizada, as redes expõem as fraturas na relação Estadosociedade. Entre o conformismo/participação e o desvio/transgressão há diversas escalas e as redes se situam entre um pólo e o outro no que se refere à relação com o Estado e com as estruturas mais antigas que detém o poder nas relações internacionais e condicionam as políticas. Quando o Estado está cumprindo os ditames da ideologia que a rede adotou, a rede não atua de forma contrária aos interesses nacionais; porém, ela pode atuar de diferentes formas para firmar a posição de inconformismo com desvios que o Estado estaria cometendo.

No mundo, o início da década de 2010 inaugura uma série de movimentos locais ou regionais. Os movimentos sociais estariam insatisfeitos com a política tradicional. Eles se internacionalizariam (difundindo-se, domesticando-se, externalizando-se), em uma lógica de novas táticas (como a de Black Bloc), novas coalizões, e novas percepções; a que pertencem movimentos pacifistas, pró-justiça global, ecologistas, antiglobalização, etc. (PORTA; TARROW, 2005). Surgem muitas ações de inspiração na democracia direta, como as ocupações de habitações, os protestos, ações diretas na internet, entre outras formas.

As "redes de indignação e esperança" que fala Castells são fomentadas pela expansão exponencial das mídias, principalmente com o avanço da "galáxia da internet". Mas como funcionam essas "redes"? Tais são formas de organização social movidas por indivíduos - a favor da dignidade, da justiça social, e contra fatores que afetam a dignidade (autoritarismos, inflação, desemprego, concentração de renda, etc.) - e buscam novas formas de participação política; o que envolve democracia direta, deliberação autônoma, cooperação, solidariedade (CASTELLS, 2013). Uma questão interessante nos novos movimentos sociais é que se caracteriza pela ausência de uma clara liderança, como se fosse uma multidão em marcha, diferente de movimentos sociais com uma liderança evidente, que direciona os atos dos participantes. Essa aparente "acefalia", todavia, esconde o fato de que uns se destacam mais do que outros. Em certo sentido, essas novas modalidades de movimento social conseguiram 

Janeiro.

se desenvolver na medida em que a mídia disseminável, a convergência, as mídias digitais sociais, e outros fatores contemporâneos, avançaram.

Pode-se dizer que hoje a formação, a confiança, e a mobilização políticas são auxiliados pelas mídias; pois a mídia consegue ativar a participação, mais que desengajar os desengajados (NORRIS, 2000). Todavia, ao invés de ver a transformação da comunicação como a verdadeira panacéia, deve-se manter em mente a dimensão política das políticas públicas; de onde vem a importância do debate sobre democracia representativa e sobre democracia direta, por exemplo. A arena política continua a mobilizar os vieses, uma vez que os sistemas de pressão permanecem atuando sobre instituições; assim a democracia, mesmo com avanços na comunicação, permanece espaço do conflito político (SCHATTSCHNEIDER, 1975). A principal mudança nas políticas públicas hoje é a estruturação do E-GOV ou governo eletrônico.

O termo surge no momento de reforma da administração pública, que busca eficiência, eficácia, efetividade, muitas vezes com gerenciamento por resultados; cria-se um modelo de operação, administração e gestão digitais, em que redes, comitês, conselhos, agências, etc., interagem (FERRER; SANTOS; SOLA, 2004). As três áreas típicas do governo eletrônico seriam: serviços de utilização direta pelos cidadãos; serviços para aumento da qualidade e eficiência da máquina pública; recursos para atuação social e controle do governo (MARTINS, 2004). Pode-se pensar em estágios do E-Gov, desde a disseminação de informação unidirecional, com um emissor e um receptor, até a participação política e a democracia digital, com papéis múltiplos (MOON, 2002). O governo eletrônico, com efeito, é uma realidade nas municipalidades, e pode gerar mais satisfação e mais confiança no governo.

Em certo sentido, os governos eletrônicos só poderiam surgir a partir dos anos 1990, quando a internet e os computadores pessoais foram popularizados. Acompanham essa tendência o surgimento da Corporação da Internet para Atribuições de Nomes e Números (ICANN) em 1998, as Cúpulas Mundial sobre a Sociedade da Informação (em 2003 e 2005') e debates recentes sobre os temas relacionados, como a Resolução da Organização das Nações Unidas sobre o direito à privacidade na internet, de 2013. O Brasil advogou a favor da iniciativa na Organização das Nações Unidas (ONU), tendo também experiências de

\footnotetext{
${ }^{6}$ Demais encontros ocorreram em maio de 2010, maio de 2011, maio de 2012, maio de 2013, junho de 2014 e maio de 2015. O próximo está previsto para maio de 2016, e todos desde 2010 ocorreram em Genebra.
} 
governo eletrônico no nível federal, como: Serviço Federal de Processamento de Dados; AliceWeb, sistema de análise das informações do Sistema Integrado de Comércio Exterior, do Ministério de Desenvolvimento, Indústria e Comércio Exterior; urnas eletrônicas no Tribunal Superior Eleitoral; pregão eletrônico; ReceitaNet, sistema do Ministério da Fazenda; blog Diplomacia Pública, do Ministério das Relações Exteriores, entre outros exemplos.

Curiosamente, no âmbito municipal tem existido maior inovação sobre as políticas públicas do que em meios estaduais ou federais, ao redor do globo. São os municípios que avançam mais na implantação do governo eletrônico se comparados com os Estados/Províncias/Condados e a União/Federação/República. Um exemplo ligado à PCRJ é o programa "Nave do Conhecimento", instituído em 2012, mais ligado a Ciência, Tecnologia, Inovação e Educação do que com a estratégia de participação social. Além do E-Gov, a inteligência do ambiente e a internet das coisas têm ampliado muito as possibilidades de real existência de uma vida "ciborgue", isto é, com união entre a vida humana e a das máquinas.

\section{O LABORATÓRIO DE PARTICIPAÇÃO DA PREFEITURA DA CIDADE DO RIO DE JANEIRO}

Algo mais sofisticado surgiria desde o Lab.Rio (Laboratório de Participação Cidadã da Prefeitura do Rio), que é criado para estimular a participação cidadã na PCRJ, além disso, integra o "Pacto para o Rio" - que visa promover e monitorar o desenvolvimento sustentável na cidade. Vale lembrar que a Conferência das Nações Unidas sobre o Meio-Ambiente e o Desenvolvimento (ou Eco-92) e a Rio+20 foram sediadas na cidade, e foram momentos de importância global para discutir a sustentabilidade. A política pública do Lab.Rio é ligada ao E-Gov. O método de construção dessa política pública é de baixo para cima, construindo a mesma através da participação direta da população pelo meio virtual e com encontros presenciais. O site é desenvolvido na plataforma "Crowdicity", usada também por: ONU; Comissão Europeia; World Wide Fund for Nature (WWF); Oxford Comittee for Famine Relief (Oxfam); National Health System (NHS); BBC; entre outros.

O Laboratório engloba os projetos: “Ágora Rio”; "ChegaJunto!”; “Conselhos da Juventude da Cidade"; "Imersão"; e "Mapeando". Eles serão comentados um por um a seguir, e, ainda que o primeiro na lista tenha antecedido a criação do Lab.Rio, ele integra junto com os outros 4 uma prática de gestão participativa integrada ao mundo virtual. Há projetos mais recentes que também serão comentados no texto. O Lab.Rio é por si a 

Janeiro.

proposta, e não há um objetivo material específico, tendo em vista que estes giram em torno do verdadeiro sentido de existência do conjunto de projetos: a participação. Sendo assim, as modalidades de participar são variadas, os resultados também, mas todos são agrupados debaixo da mesma política pública "constituinte", que pode vir a ter dimensões distributivas e redistributivas (LOWI, 1972), principalmente quando o poder municipal executar propostas.

Todas as atividades do laboratório são orientadas por conceitos e escalas instituídos pela Associação Internacional para Participação Pública. No sítio do Lab.Rio foram obtidas as informações relativas ao próprio e aos seus projetos, incluindo as informações sobre os cinco compromissos que norteiam as ações: informar; consultar; envolver; colaborar; empoderar. Além disso, há princípios que orientam o Laboratório de Participação: 1. "A cidade é um direito de todxs xs cidadxs"; 2. "A participação social é um direito de todxs xs cidadxs"; 3. "A participação social é um instrumento de mudança e melhorias"; 4. "Transparência, honestidade, clareza e fiscalização são fundamentais para que a participação seja efetiva". A seguir há descrições do funcionamento de como funcionam os diversos projetos associados. Este trabalho não é fruto de etnografia, por isso espera-se ampliar o entendimento sobre o objeto que está sendo discutido no artigo sem uma descrição densa.

\subsection{O “ÁGORA RIO”.}

De acordo com o site da PCRJ: “o Ágora Rio é uma rede social para cidadãos e cidadãs cariocas proporem e debaterem políticas públicas com as secretarias e órgãos municipais". Além disso, a plataforma colaborativa governamental para discutir políticas públicas é marcada pela "Gameficação/Ludificação", que consiste em usar mecânicas de jogos, com objetivo de incrementar a participação, engajamento, envolvimento dos participantes. São sinais disso a existência do conceito "desafio", a existência de certas propostas "vitoriosas", e de perfis específicos. É preciso entender o problema e os objetivos do programa dentro do escopo das políticas públicas da PCRJ.

O problema a ser resolvido é o engajamento da população diretamente com a prefeitura. Assim sendo, os temas englobados nesse engajamento variam com o tempo. O primeiro tema foi o legado a ser deixado depois dos Jogos Olímpicos e Paralímpicos de 2016; já o segundo tema é o da mobilidade urbana. Pode-se dizer que os objetivos do "Ágora" estão ligados à ampliação da participação da população - principalmente no processo de 
formulação de políticas públicas e no agendamento de questões para o poder público. De acordo com o site, foi criado com o objetivo de "devolver ao cidadão sua participação na construção da cidade". Sendo vetor da gestão colaborativa e de processo de tomada de decisões de forma democrática e ligada à era da informação.

Vejamos agora as etapas e cronogramas do Ágora Rio. Ele teve início em 09/09/2014. O primeiro desafio foi sobre o Legado Olímpico e Paralímpico de 2016, subdividido em: envio de ideias (setembro e outubro); discussão das propostas (novembro); votação online (10 a 17 de novembro); entrega de documento ao prefeito (04/12). Na última etapa, há uma avaliação pelo prefeito e discussão das propostas através de um hangout na internet. Sobre o "Desafio Ágora Rio Legado Olímpico", o primeiro ciclo, pode-se dizer que é possível analisar seus resultados. Das 25 propostas selecionadas para que o prefeito discutisse com a população, somente 12 não foram incorporadas, e somente 3 foram completamente incorporadas ao planejamento, as 10 demais foram parcialmente incorporadas. Tais conclusões poderiam ter sido extraídas da videoconferência que marcou o final deste ciclo, presente no YouTube ao longo de 2015. Muitas das propostas selecionadas diziam respeito a questões urbanas, em especial ligadas à mobilidade, planejamento, e à sustentabilidade.

O segundo desafio, atual, segue moldes semelhantes. O tema passou a ser o da mobilidade urbana. As etapas ganharam novos nomes, e se reconfiguraram. A primeira etapa é o Engajamento (19/01 a 22/02); a segunda é a Proposição (23/02 a 03/04); a terceira é a Curadoria (04/04 a 19/04); a quarta é a votação (20/04 a 12/06); a Avaliação ocorre entre 13/06 e 25/06. Espera-se que após essa última etapa 10 propostas mais votadas sejam avaliadas pelo grupo responsável pelo Plano de Mobilidade Urbana Sustentável do município. O encerramento se dará com uma conferência online ao vivo com o prefeito.

\subsection{O “CHEGAJUNTO!”.}

O “ChegaJunto!" volta-se às crianças e adolescentes, que participam por um dia de um exercício com dois momentos. O primeiro momento é dedicado a formulação de projetos e a simulação de orçamentos, de formas lúdicas, pedagógicas, tendo os alunos liberdade para alocar recursos orçamentários em diversas secretarias para fins diversos. O segundo momento é o que os jovens quais elencam as propostas prioritárias para a gestão municipal, depois expressam aos secretários. Os últimos explicam como os processos se dão na prática e comentam as propostas dos jovens. Isso garante a participação jovem, e auxilia 

Janeiro.

no interesse deles pela "coisa pública”, nesse sentido é um empoderamento e um esforço de conscientização, que pode trazer resultados positivos para os participantes jovens no futuro. No curto prazo, auxilia o processo de formulação dos pertencentes ao governo municipal.

\subsection{O CONSELHO DA JUVENTUDE DA CIDADE}

A ideia do Conselho da Juventude é trazer um grupo de jovens, selecionados pelo Lab.Rio, para discutir o planejamento estratégico da cidade. Foram selecionados 100 jovens de por volta de 600 inscritos, que seguem critérios de representação por sexo, distribuição territorial, etc. Existem grupos de trabalho que são formados para lidar com temas específicos: Cultura; Educação; Diversidade e Liberdade Religiosa; Empreendedorismo; Regimento Interno; Comunicação; Resiliência e Sustentabilidade. Uma plenária prevista para dezembro de 2015 apresentará resultados do Conselho. Temas pertencentes ao Laboratório foram ressaltados em reuniões, como: democracia; participação; inclusão; geração de transformações práticas; mobilização ininterrupta. Também discutiram-se formas de dar mais visibilidade à iniciativa, como criação de página no Facebook, promoção de eventos públicos, aproximação com secretarias municipais. Por fim, pode-se destacar proposta de criação de um banco de ideias para o Conselho.

Surge também no campo do planejamento participativo o projeto "Visão Rio 500", que pretende estabelecer estratégias para os próximos 50 anos para a cidade. A ideia é complementar os planejamentos estratégicos de 4 anos (como os de 2009-2012 e de 20132016), feitos no modelo clássico “Top-Down”, e ao invés, criar algo para o longo prazo “de baixo para cima”. Antes do início das atividades, os participantes são estimulados a conhecerem iniciativas municipais anteriores ao projeto, depois são pensados problemas, oportunidades e diretrizes para o período de agora até 2065. Em seguida, são propostas ações para os próximos 4 anos, através de consultas a especialistas, de análise de dados, de escuta dos cidadãos e de fóruns de discussão. As áreas temáticas nas quais se enquadram as propostas foram estabelecidas seguindo a divisão por temas dentro do planejamento estratégico. No fim do ciclo, tanto o Plano Estratégico 2017-2020 quanto a Visão Rio 500 serão lançados, em março de 2016, com vigência a partir de janeiro de 2017. 


\subsection{O PROJETO "IMERSÃO”}

O projeto "Imersão" se iniciou em janeiro de 2015, e segue um esquema mais “offline" em comparação com os outros. Ele é centrado em informação e consulta, logo tem uma dimensão diferente do Ágora. Orienta-se por igualdade de gênero e por uma distribuição igualitária de regiões ${ }^{7}$. Os participantes escolhem três temas associados à gestão municipal no momento de inscrever-se, e são agrupados conforme os interesses; há ainda um quarto tema, que é Planejamento \& Gestão, abordado em todos os grupos, independente das preferências temáticas. Cada grupo tem 30 pessoas que são selecionadas via processo seletivo aberto.

Dura um dia (manhã e tarde). Primeiro, dedicam-se os envolvidos ao debate com equipes técnicas e gestoras de secretarias e autarquias municipais. Em seguida, são conhecidas instalações, equipamentos e obras. Por colocar em contato com o público o corpo técnico, secretariado, e de gestão há oportunidade de criar relação mais estreita entre eles. Seria um projeto análogo ao “ChegaJunto!”, com faixa etária de idade mais elevada, caso não houvesse também o compromisso de proporcionar maior conhecimento de processos e funcionamento dos processos decisórios da gestão municipal.

\subsection{A FERRAMENTA “MAPEANDO”}

Enquanto o "Ágora Rio" dura meses, o "Mapeando" é praticamente instantâneo; e, nesse sentido, a "Imersão" seria uma espécie de meio-termo. A ferramenta "Mapeando" trabalha com o geoprocessamento, com o processo de utilização de dados geográficos, cartográficos, dentro de um sistema de referências. Ela tem por base de referência as demandas por bens e serviços públicos dos cidadãos que participam. A pessoa se cadastra, usando um email válido, aponta no mapa onde ela quer que a PCRJ aja, e o que ela demanda; e isso cria um ponto dentro do mapa que existe na tela. Esse ponto tem uma cor de acordo com a demanda que a pessoa expressa, o que, para fins de utilização é útil, facilita. Os demais usuários do sistema, que é on-line, podem visualizar e comentar demandas das pessoas. $\mathrm{O}$

\footnotetext{
${ }^{7}$ Em seu início foi pensado para ter uma restrição etária entre 16 e 26 anos, mas não seguiu esse parâmetro depois, tendo acolhido pessoas de faixa de idade bem superior; em sua fase inicial contou com mais de 100 inscritos. Isso realça os Conselhos da Juventude. Ainda sobre esse grupo cuja vivência se situa entre a infância e a fase adulta, pode-se realçar a importância dela nos movimentos sócio-políticos que pressionaram por mudanças desde a década de 2000, incluindo os movimentos dos anos 2010, muito fortes em junho de 2013.
} 

Janeiro.

"Mapeando" então trabalha com fluxo contínuo de participações, e periodicamente faz relatórios aos secretários e ao prefeito sobre as demandas mais populares.

\section{CONSIDERAÇÕES FINAIS}

Recentemente, o poder público eleito precisa se reconfigurar, tendo em vista tendências variadas. Mudam as formas de lidar com a informação, surgem novas tecnologias, novas pressões estruturais e internacionais se fazem presentes; ao mesmo tempo, se refinam as maneiras de se influenciar nas ruas e as formas de se fazer a gestão municipal no Brasil. Desde experiências de gestão participativa pelo país, passando pelas jornadas nos anos 1990, 2000 e em 2013, a prerrogativa decisória se mantém na liderança do poder executivo. No final de 2014 surge o Lab.Rio, fruto da sua época, de E-Gov, de inteligência coletiva, da democracia participativa, dos atores em rede e em ruas ativos, altivos, autônomos.

Uma das respostas às demandas legítimas da população foi dar à população mais voz dentro do governo. Em setembro de 2014, surge o Ágora Rio, em dezembro de 2014, o Lab.Rio; em 2015, 40 conselhos e comissões nacionais são existentes, influenciando as políticas públicas, e o governo federal, em julho deste ano, lançou o programa "Dialoga Brasil", que funciona de forma semelhante ao Ágora. Para entregar à população aquilo que é apresentado como demanda, uma plataforma que discuta temas abordados nas passeatas como os legados dos megaeventos esportivos (Copa do Mundo, Olimpíadas, etc.), a mobilidade urbana, entre outros, surge como uma adequação às demandas do povo, e, ao mesmo tempo, às demandas do seu tempo de eficiência, eficácia, efetividade, com agilidade e desburocratização. Aliado a isso está a expansão do governo eletrônico.

O investimento administrativo nessa direção geraria a ampliação da cidade no ranking das cidades globais e das cidades inteligentes. O evento internacional Fórum "SmarterCities" foi sediado no Rio de Janeiro em novembro de 2011, provando a importância para a cidade, e projetando a mesma internacionalmente. Outras cidades, como a de Curitiba, a do Recife, a de São Paulo, só para ficar restrito ao Brasil, também buscam, cada qual da sua maneira, desenvolver-se como cidades inteligentes. Portanto, é uma tendência real e pujante no mundo de hoje. A experiência do “Ágora Rio" integra o Lab.Rio, que pode ser expandido e ter muitos outros programas ainda. Cabe não só a Prefeitura da Cidade do Rio de Janeiro, mas à população propor. Fica a inovação, todavia, refém de transições políticas, que podem confirmá-la, aprofundá-la, ou simplesmente exterminá-la. A história ensina. 


\section{REFERÊNCIAS}

AVRITZER, L. 2000. Teoria democrática e deliberação. Lua Nova: Revista de Cultura e Politica, São Paulo, N. 49, p. 25-46.

BADIE, B. 1995. O fim dos territórios: ensaio sobre a desordem internacional e sobre a utilidade social do respeito. Lisboa: Instituto Piaget.

BARBOSA, L. 2008. Sociedade de consumo. Rio de Janeiro: Zahar Ed.

BENNETT, J.; MEDRADO, A. M.; STRANGE, N. 2012. Produzindo projetos de mídia "multiplataforma" para a televisão pública no Reino Unido: a BBC e o setor independente de produção. Contemporanea, comunicação e cultura, Salvador, v. 10, n. 02, p. 302-323.

BEZERRA, M. O. 2012. Formas de participação popular e produção de interesses coletivos - observações a partir de duas experiências no Estado do Rio de Janeiro. In: Heredia, B. de; Palmeira, M. (Orgs.). Política, governo e participação popular: conselhos, orçamento participativo e outras experiências. Rio de Janeiro: 7 Letras, p. 111-166.

BIRKLAND, T. 2011. An Introduction to the Policy Process: theories, concepts, and models of public policy making. London: M. E. Sharp.

BRAGA, B. S.; BRAGA, R. S. 2015. Democracia participativa no Rio de Janeiro (1986-1988). Rio de Janeiro: Contraponto.

CABRAL, A. V. 2011. A Web 2.0 como agenciamento de audiências pelos grupos midiáticos contemporâneos. Logos, Rio de Janeiro, v. 34, n. 01, p. 152-165.

CASTELLS, M. 2002. A sociedade em Rede. A Era da Informação: economia, sociedade e cultura. Volume 1.1 São Paulo: 1 Paz Terra. de Janeiro: Zahar. 2013. Redes de indignação e esperança: movimentos sociais na era da internet. Rio

CERVI, E. 2013. Mundo virtual, poder real: mesmo sob novas condições a alocação de poder político não necessariamente muda. In: Lukas Lingenthal; Gregory John Ryan; Reinaldo Themoteo (Org.). Democracia Virtual. Rio de Janeiro: Konrad Adenauer, p. 11-30.

COLONOMOS, A. 2004. O ator em rede colocado à prova do internacional. In: MarieClaude Smouts (Org.). As novas Relações Internacionais: práticas e teorias. Brasília: Editora Universidade de Brasília, p. 195-215.

FERRER, F.; SANTOS, P.; SOLA, P. C. 2004. Governo digital: origem do conceito e modelo para discussão. In: Florencia Ferrer; Paula Santos (Org.). E-government: o governo eletrônico no Brasil. São Paulo: Saraiva, p. 114-119.

FORD, S.; GREEN, J.; JENKINS, H. 2013. Spreadable Media: creating value and meaning in a networked culture. Nova Iorque: NYU Press.

FUNG, A. 2006. Democratizing the policy process. In: Michal Moran; Martin Rein; Robert Goodin (Eds.). The Oxford Handbook of Public Policy. Oxford: Oxford University Press. p. 669685.

GARCÍA-CANCLINI, N. 2006. Consumidores e cidadãos: conflitos multiculturais da globalização. Rio de Janeiro: Editora UFRJ. 

Janeiro.

GASTIL, J.; JOHNSON, C. 2015. Variations of Institutional Design for Empowered Deliberation. Journal of Public Deliberation, Louisville, Vol. 11, Issue 1, Art. 2, p. 1-32.

GOHN, M. da G. 2011. Teoria dos Movimentos Sociais: paradigmas clássicos e contemporâneos. São Paulo: Edições Loyola.

LÉVY, P. 1999. Cibercultura. São Paulo: Editora 34.

LOWI, Theodore. 1972. Four systems of policy, politics, and choice. Public Administration Review, Washington D.C., Vol. 32, n. 4, p. 298-310.

MARTINS, W. M. 2004. Classificação das atividades de governo eletrônico e as oportunidades de aperfeiçoamento das relações sociedade/Estado. In: Florencia Ferrer; Paula Santos (Org.). E-government: o governo eletrônico no Brasil. São Paulo: Saraiva, p. 16-24.

MASSARDIER, G. 2003. Politiques et actions publiques. Paris: Armand Collin.

MCKEEVER, D.; RAPPORT, M. 2013. Trazendo a sociedade de volta: 1848 e 2011. In: Gregory John Ryan; Lukas Lingenthal; Reinaldo Themoteo (Org.). Democracia Virtual. Rio de Janeiro: Konrad Adenauer, p. 121-134.

MIZUKAMI, P.; REIA, J.; VARON, J. 2014. Mapeamento da mídia digital no Brasil. Rio de Janeiro: Escola de Direito do Rio de Janeiro da Fundação Getúlio Vargas. Centro de Tecnologia e Sociedade.

MOON, M. J. 2002. The Evolution of E-Government among Municipalities: Rhetoric or Reality? Public Administration Review, Washington D.C., v. 62, n. 4, p. 424-433.

NORRIS, P. 2000. A virtuous circle: political communication in postindustrial societies. Cambridge: Cambridge University Press.

O’DONNELL, G. 1998. Accountability horizontal e novas poliarquias. Lua Nova: Revista de Cultura e Política, São Paulo, n. 44, p. 27-54.

PATEMAN, C. 1992. Participação e teoria democrática. São Paulo: Paz e Terra.

POGREBINSCHI, T.; SANTOS, F. 2011. Participação como Representação: o impacto das Conferências Nacionais de Políticas Públicas no Congresso Nacional. DADOS, Rio de Janeiro, Vol. 54, n. 3, p. 259-305.

PORTA, D. D.; TARROW, S. 2005. Transnational processes and social activism: an introduction. In: Porta, D. D.; Tarrow, S. (Org.). Transnational protests and global activism. Oxford: Rowman \& Littlefield Publishers, Inc., p. 1-17.

SCHATTSCHNEIDER, E. E. 1975. The semisovereign people: a realist's view of democracy in America. Hinsdale: The Dryden Press.

SOUZA, H. de. 2009. Como se faz análise de conjuntura. Petrópolis: Vozes.

SUPPO, H. R. 2015. Internet e Democracia. In: Themoteo, R. (Org.). Cadernos Adenauer. Internet e Sociedade. Vol. XVI, N. 3. Rio de Janeiro: Konrad Adenauer, p. 19-45. 